\title{
Chronic Ayurvedic medicine use associated with major and fatal congenital abnormalities
}

\author{
Although there are potential associations between lead exposure during pregnancy and adverse \\ pregnancy outcomes, there are limited data on whether in-utero lead exposure is associated with \\ major congenital abnormalities. We describe a case of a major congenital renal abnormality, which \\ resulted in severe pulmonary hypoplasia and neonatal death, that was potentially associated with \\ maternal chronic lead ingestion via an Ayurvedic medicine throughout pregnancy.
}

\section{Clinical record}

A 28-year-old primigravida was referred to a maternalfetal specialist because a fetal ultrasound at 20 weeks showed oligohydramnios, absence of the right kidney and a small echogenic left kidney with poor corticomedullary differentiation, and intrauterine growth restriction. She had a history of lethargy throughout her pregnancy and a normocytic anaemia with a haemoglobin level of $95 \mathrm{~g} / \mathrm{L}$ (reference interval [RI], 97-148 g/L) at 24 weeks' gestation and $88 \mathrm{~g} / \mathrm{L}$ (RI, 95-150 g/L) at 30 weeks' gestation. Her white cell count and platelet count were normal at 24 weeks' and 30 weeks' gestation. Liver and renal function test results, and serum vitamin $\mathrm{B}_{12}$, folate and ferritin levels were also within normal limits at both 24 weeks' and 30 weeks' gestation. Chorionic venous sampling performed at 24 weeks did not detect any significant genomic abnormalities. At 30 weeks' gestation, the maternal blood film showed basophilic stippling and her blood lead level (BLL) was high at $3.2 \mu \mathrm{mol} / \mathrm{L}(\mathrm{RI},<0.48 \mu \mathrm{mol} / \mathrm{L})$ or $67 \mu \mathrm{g} / \mathrm{dL}$ (RI, $<10 \mu \mathrm{g} / \mathrm{dL}$ ). The toxicology unit was consulted and chelation was commenced, including oral dimercaptosuccinic acid (DMSA) at a dose of $10 \mathrm{mg} / \mathrm{kg}$ three times a day for 5 days followed by $10 \mathrm{mg} / \mathrm{kg}$ twice daily for 14 days. Three weeks after chelation, her BLL was 0.7 $\mu \mathrm{mol} / \mathrm{L}(14.4 \mu \mathrm{g} / \mathrm{dL})$. MBBS, FACEM

Jenni Sokol MBBS, FRACP, FCICM

Jayshree Ramkrishna MD, FRANZCOG, DDU

Shaun L Greene MBChB, MSc(MedTox) FACEM

1 Victorian Poisons Information Centre Austin Health, Melbourne, VIC

2 Monash University, Melbourne, VIC

3 Clinical Toxicology Service

St Thomas' Hospital,

NHS Foundation Trust, London, UK

4 King's College London, London, UK

5 Royal Women's Hospital Melbourne, VIC

anselm.wong@ austin.org.au

doi: 10.5694/mjal5.00636

For the previous 6 months, the patient had been taking two tablets per day of an Ayurvedic medicine, prescribed by a practitioner in India, that she was self-importing to Australia. Analysis of these tablets (performed by DTS Food Laboratories, a National Association of Testing Authorities-accredited laboratory) using inductively coupled plasma mass spectrometry, a process used to detect metals and non-metals, showed a lead content of $47 \%$, small amounts of mercury (1.7\%), and arsenic $(<0.01 \%)$. Urine arsenic and mercury levels were within normal limits. No other sources of lead exposure or ingestion were found.

Fetal growth improved after chelation therapy commenced; however, further ultrasound scans of the fetus showed diminished left renal tissue with progression to anhydramnios by 30 weeks' gestation. By 34 weeks' +5 days' gestation, there was no fetal renal tissue visible on ultrasound. The family received extensive counselling from the neonatal and renal specialists and the paediatric toxicologist, with consideration as to whether to dialyse the baby if chelation was needed and if the expected related respiratory failure was considered survivable postnatally.

Three days before an elective caesarean section at 39 weeks, the mother received intravenous calcium disodium edetate $40 \mathrm{mg} / \mathrm{kg}$ twice daily to decrease her lead concentrations before delivery. She gave birth to a $3.14 \mathrm{~kg}$ baby who had severe hypoxic and hypercapnic respiratory failure and a small right pneumothorax as a result of pulmonary hypoplasia, and severe contractures with bilateral dislocated hips, each resultant of the antenatal anhydramnios. The baby did not have typical facies of Potter sequences or other congenital abnormalities associated with Potter syndrome. Renal ultrasound showed no left renal tissue and a severely dysplastic right kidney of $1 \mathrm{~cm}$ diameter. The cord BLL at delivery was low at 0.37 $\mu \mathrm{mol} / \mathrm{L}(8.0 \mu \mathrm{g} / \mathrm{dL})$. Given the low BLL, chelation was not initiated. The baby died 2 days later from severe respiratory failure owing to poor antenatal pulmonary development, a result of the severe renal dysgenesis. At autopsy, the BLL was $0.55 \mu \mathrm{mol} / \mathrm{L}(11.5 \mu \mathrm{g} / \mathrm{dL})$ and there was severely hypoplastic and multicystic renal tissue bilaterally (right kidney, 15 g; left kidney, 16 g), with normal ureters and bladder. Three weeks' postpartum, the mother's BLL was $0.8 \mu \mathrm{mol} / \mathrm{L}(17.3 \mu \mathrm{g} / \mathrm{dL})$.

\section{Discussion}

Anaemia during pregnancy is common and iron deficiency is a common cause. However, normocytic anaemia in the absence of other causative factors requires further investigation using blood film analysis. Basophilic stippling on blood film is associated with lead toxicity, arsenic toxicity, thalassaemia, sideroblastic anaemia, thrombotic thrombocytopenic purpura and hereditary pyrimidine $5^{\prime}$ nucleotidase deficiency. ${ }^{1}$ The combination of basophilic stippling with unexplained anaemia needs further investigation, and questions regarding potential sources of lead or arsenic exposure need to be asked. Other common sources of lead include occupational exposure, fishing sinkers, old paint (before 1960), retained bullets and pottery.

During pregnancy, chronic lead toxicity can present with anaemia and lethargy, peripheral neuropathy, hypertension, liver and renal dysfunction, abdominal pain and, in 
severe cases, encephalopathy. ${ }^{2}$ Long-term effects on maternal and fetal IQ are also a concern.

Lead crosses the placenta at as early as 12-14 weeks' gestation and is mobilised from maternal bone during the formation of the fetal skeleton. Studies have shown that $85 \%$ of cord BLLs come from maternal bone stores. ${ }^{2}$ Although there are potential associations between lead exposure during pregnancy and adverse pregnancy outcomes, including spontaneous abortion, pregnancyrelated hypertension, low birth weight and neurobehavioural development, the literature is less clear on whether there is an association between major congenital abnormalities and lead toxicity during pregnancy. ${ }^{2,3}$

One case report describes an asymptomatic female worker with occupational lead exposure who had a BLL of $62 \mu \mathrm{g} / \mathrm{dL}$ at 8 weeks' gestation and was removed from exposure with a reduction of BLL to $5 \mu \mathrm{g} / \mathrm{dL}$ at 14 weeks' gestation. The infant developed VACTERL association (vertebral anomalies, anal atresia, cardiac defects, tracheo-esophageal fistula and/or esophageal atresia, renal and radial anomalies, and limb defects); it was not possible to determine whether this was caused by the lead toxicity. ${ }^{4}$ Another case involved a mother with a BLL of $31 \mu \mathrm{g} / \mathrm{dL}$ at 21 weeks' gestation from a retained bullet. There were neurological, cardiovascular and pulmonary abnormalities at birth but no functional abnormalities at 10 years of age. ${ }^{5}$

In our case, the mother had been taking Ayurvedic medication for 6 months spanning the period before pregnancy and during the first trimester during organogenesis. The baby had renal abnormalities (agenesis of one and absence of the other kidney), along with pulmonary hypoplasia and anhydramnios. The risk of nephrotoxicity increases proportionally with increasing BLL, and effects on glomerular filtration have been reported at a BLL $<20 \mu \mathrm{g} / \mathrm{dL}^{6}$ Although it is not possible to be certain that these abnormalities were caused by the lead toxicity, a high BLL was present on investigation.

Evidence for chelation therapy for lead toxicity during pregnancy is limited to animal data and case studies. ${ }^{2}$ Removal from ongoing exposure is key to the treatment of any patient with heavy metal toxicity. DMSA was administered in this case and there have been conflicting animal studies on whether DMSA increases the risk of fetal toxicity secondary to lead or whether it significantly reduces the lead concentration without harm. Chelation during the first trimester is controversial because this is the period of organogenesis; therefore, the potential benefit of chelation has to be balanced against the unknown risks of the chelation agents on fetal outcome. Generally, unless the mother is encephalopathic or has other markers of severe lead toxicity, chelation would be deferred until at least the second trimester. ${ }^{7}$ In our case, consideration was given as to which chelating agent, if needed, could be used for the baby. Given the fetus and baby had minimal kidney tissue, an intravenous chelating agent may have caused nephrotoxicity through deposits of chelation complexes. Oral succimer via a nasogastric tube was to be the chelating agent of choice, as it would not have those same concerns of nephrotoxicity.

The popularity of traditional medicines has been increasing in Asia, North America and Australasia. ${ }^{8}$ Ayurveda is the most widely practiced traditional medicine system on the Indian subcontinent. The addition of heavy metals into Ayurvedic preparations may either be purposeful or a result of contamination. During pregnancy, there is an increased recommended iron intake of $50 \%$ compared with that for women of childbearing age. The number of women substituting Ayurvedic medicine for iron supplementation during pregnancy and to what extent is unknown. In a study from the United States, an analysis of 70 Ayurvedic products showed that 14 (20\%) contained enough heavy metals to be over the recommended maximum amounts. ${ }^{9}$ There is existing legislation to help regulate the provision of Ayurvedic and herbal medicines in the United Kingdom and the US. In Australia, the Therapeutic Goods Administration (TGA) allows listing of complementary medicines if the names of the ingredients are provided to the TGA; however, testing of content (eg, for safety) is not required for such listing. ${ }^{10}$ In addition, the purchase of these medications for personal use from overseas and their availability over the internet can prove challenging to monitor.

Health care practitioners and consumers need to be aware of the potential for heavy metal toxicity to be associated with the use of Ayurvedic medications. A focused drug history including traditional remedies should be undertaken in all patients. Pregnant patients need to know the side effects of medications prescribed throughout pregnancy and the risks associated with taking complementary medicine, especially given the "loopholes" in content testing by regulatory agencies not only in some countries overseas but also in Australia.

Acknowledgements: We thank Kate Hodgson of Royal Women's Hospital, Melbourne, for her assistance in writing this case report, and all the staff involved in managing the patients.

Competing interests: No relevant disclosures. ․

(c) 2015 AMPCo Pty Ltd. Produced with Elsevier B.V. All rights reserved.

References are available online at www.mja.com.au. 
1 Cheson BD, Rom WN, Webber RC. Basophilic stippling of red blood cells: a nonspecific finding of multiple etiology. Am J Ind Med 1984; 5: 327-334.

2 Ettinger AS, Wengrovitz AG, editors. Guidelines for the identification and management of lead exposure in pregnant and lactating women. Atlanta: US Department of Health and Human Services, 2010. http://www.cdc.gov/nceh/lead/ publications/leadandpregnancy2010.pdf (accessed Jul 2015).

3 Taylor C, Goldry J, Edmond A. Adverse effects of maternal lead levels on birth outcomes in the ALSPAC study. BJOG 2015; 122: $322-328$.

4 Levine F, Muenke M. VACTERL association with high prenatal lead exposure: similarities to animal models of lead teratogenicity. Pediatrics 1991; 87: 390-392.

5 Raymond LW. Maternal-fetal lead poisoning from an old slug: 10-year follow-up. J Matern Fetal Neonatal Med 2009; 22: 543-544.
6 US Department of Health and Human Services. Toxicological profile for lead. August 2007. http://www.atsdr.cdc.gov/ toxprofiles/tp13.pdf (accessed Jul 2015).

7 Brown MJ. Role of chelation during pregnancy in the lead poisoned patient. J Med Toxicol 2013; 9: 344-346.

8 Lynch E, Braithwaite R. A review of the clinical and toxicological aspects of "traditional" (herbal) medicines adulterated with heavy metals. Expert Opinion Drug Safe 2005; 4: 769-778.

9 Saper RB, Kales SN, Paquin J, et al. Heavy metal content of Ayurvedic herbal products. JAMA 2004; 292: 2868-2873.

10 Therapeutics Goods Administration. Listed medicines: the role of Australia's medicines regulator. 27 June 2013. http://www.tga.gov.au/community-qa/listed-medicinesrole-australias-medicines-regulator (accessed Jul 2015). 